\title{
Developing a sustainable forest biomass industry: case of the US northeast
}

\author{
D. Damery ${ }^{1}$, J. Benjamin ${ }^{2}$, M. Kelty ${ }^{1} \&$ R. J. Lilieholm ${ }^{2}$ \\ ${ }^{1}$ Department of Natural Resources Conservation, \\ University of Massachusetts-Amherst, USA \\ ${ }^{2}$ School of Forest Resources, University of Maine, USA
}

\begin{abstract}
Heightened interest in renewable energy has produced a spate of new research into the feasibility of forest biomass as a feedstock. The US Northeast is one of the few regions worldwide that supports both a large forest resource and a relatively high population density and hence energy demand. This paper outlines economic, ecological, and social considerations that must be addressed in order to achieve a sustainable forest biomass industry. Issues include sustaining the forest resource, understanding forest landowner attitudes, ensuring adequate harvesting capacity and related forest industry infrastructure, devising recommended harvest practices, demand analysis, and the development of a range of technologies that will be vying for the forest biomass resource. Recent studies focusing on sustainable supply issues include consideration of species growth and harvesting rates, as well as development of best practices to insure long-term site productivity and stream water quality. The capacity of the existing forest industry must expand with the additional demand for increased production of forest biomass. Public policy, landowner attitudes, and consideration of other social values will all play important roles in how the forest biomass industry develops. Though the research, data, and examples presented focus on the US Northeast, many of these issues have broad application to other regions of the world given appropriate consideration for local differences.
\end{abstract}

Keywords: forest biomass, sustainable, renewable energy, supply, harvest, forest landowners, social attitudes, human dimensions, forest policy. 


\section{Introduction}

The recent spike in interest in renewable energy has produced a spate of new research into the feasibility of forest biomass as a feedstock. The US Northeast is one of the few regions that support both a large forest resource and a relatively high population density and hence energy demand. Indeed, the six states that comprise New England (Connecticut, Maine, Massachusetts, New Hampshire, Rhode Island and Vermont) were among the first to be colonized by Europeans, and today remain densely populated. Forest cover has varied widely over the past 300 years. Prior to colonization the land was completely forested. Forest cover then declined with initial population expansion but has recovered over the past 125 years [1]. Currently the New England region has a population of 14.3 million [2] with over $81 \%$ forest land cover totalling over 32 million acres [3].

DiMaio and O'Connor [4] highlight the need to balance the traditional three areas of sustainability (ecology, economics, and social values) in the context of biomass for energy. The sustainable use of forest biomass has the potential to improve air quality, substitute for non-renewable resource extraction, and reduce greenhouse gas emissions that impact global warming. This paper addresses some of the emerging concerns surrounding the growing interest in forest biomass including: What is a sustainable level of forest biomass harvesting? What are the best practices for maintaining forest ecosystem health? What is the current forest industry capacity and how is it likely to change? Who owns the forest and what are owner attitudes toward potential increases in harvest activity associated with biomass material? What is the role of policy in managing these various issues?

\section{Economic sustainability}

The first leg in the triangle of sustainability that we address is economics. For any renewable resource, demand must be balanced with supply. The following sections will address emerging issues, in the case of the US Northeast, regarding emerging demand for the resource and constraints on supply.

\subsection{Demand for forest biomass}

Forest biomass is currently, or will in the future be, used for heating buildings, generating electricity, and producing a wide variety of liquid fuels, chemicals and other products [5]. Using forest biomass to generate electricity and process heat is perceived as a bridge technology before solar photovoltaics and wind energy become economically viable on a widespread basis [6]. The US Department of Energy (DOE) estimates that biomass accounted for $5.9 \%$ of energy supplied in the Northeast in 2006 [7].

DOE's definition of biomass includes both wood and waste. Humans, from the beginning, have relied on the wood resource as a source of heat. Energy demand for residential and commercial building in the US Northeast is dominated by the need for heat in cold-weather months. Currently, forest 
biomass takes a number of forms when it is used to generate heat or electricity, including firewood logs, chips, sawdust, pellets, and fiber-bricks.

In addition to forest biomass being used for heat, there is a renewed and growing trend in wood-based electricity production. In the Northeast a number of states have developed Renewable Portfolio Standards (RPS) that mandate electricity suppliers demonstrate that an increasing amount of their electricity is generated from renewable sources. The total biomass electricity generating capacity in the Northeast in 2006 is estimated to be 1,663 MW [8]. The current RPS legislation is driving a number of project proposals that will soon increase this capacity.

Using efficiencies and conversion factors after Timmons et al. [9], this represents 160 trillion BTU of biomass energy demand, or $77 \%$ of the total biomass energy supplied as estimated by the US DOE [7].

Market-based economics dictates that resource use should gravitate towards its "highest and best use." Traditionally, the material harvested from the forest has been used to produce many products. In an approximate order of value, these include: veneer logs, sawlogs, pulpwood, cordwood, and chips for fuel. The higher value uses provide an economic constraint on the volume of forest biomass "chips" that might be diverted for other uses.

Harvest and the demand for higher value forest products currently constrain the quantity of forest biomass chips in the US Northeast [5,10,11]. Silvicultural practices, particularly in Southern New England, have focused on the production of high-value sawtimber trees [10]. Existing harvesting equipment is tailored for working with higher value sawlog and roundwood products, and not for a new incremental forest biomass supply. New forest biomass material will consist of cull and small-diameter trees, and harvest residues consisting of upper stems and branches [10]. Up to this point in time there has not been a sufficient market for this material that would justify the high cost of harvesting, processing and transporting this low-value, low bulk density material. Current technologies are not economic for sustainable harvest and processing of the forest biomass material alone. That is, given current market prices and harvesting costs, forest biomass must be harvested alongside traditional higher-value products such as sawlogs.

In the near-to-medium future a wide variety of additional products may be vying for forest biomass as a feedstock. Potential large-scale users of this resource would convert this material into ethanol, biodiesel, acids, char, chemicals and pharmaceuticals [5]. Business plans for these products need to carefully assess the competitive demand for cellulosic feedstocks - including forest biomass - as they move forward into commercial production.

\subsection{Supply of forest biomass}

The forest resource in New England varies somewhat from south to north [5]. The northern reaches, particularly Northern Maine are dominated by spruce (Picea sp.), pine (Pinus strobus), and fir (Abies balsamea). The south (Massachusetts, Connecticut and Rhode Island) is characterized more by mixed temperate hardwood stands. Smith et al. [3] list 23 different species types 
comprising the Northeast forest. Table 1 shows that the Northeast forest holds a little more than 1.3 billion cubic meters of growing stock. About $44 \%$ of the volume is in softwood species including spruce, pine and fir. Hardwood species - particularly red maple (Acer rubrum), hard maple (Acer saccharum), and red oak (Quercus rubra) - comprise the other $56 \%$ of growing stock volume.

Table 1: $\quad$ New England growing stock volume by species, 2002 [1].

\begin{tabular}{lr}
\hline Species group & $\begin{array}{r}\text { Millions of } \\
\text { cubic meters }\end{array}$ \\
Other yellow pines & 3.77 \\
White \& red pines & 183.35 \\
Jack pine & 0.06 \\
Spruce \& balsam fir & 235.74 \\
Eastern hemlock & 107.01 \\
Other softwoods & 64.82 \\
Select white oaks & 13.14 \\
Select red oaks & 77.96 \\
Other white oaks & 2.24 \\
Other red oaks & 26.79 \\
Hickory & 8.07 \\
Yellow birch & 59.27 \\
Hard maple & 133.12 \\
Soft maple & 185.11 \\
Beech & 59.81 \\
Tupelo (black gum) & 0.76 \\
Ash & 41.12 \\
Basswood & 3.00 \\
Yellow poplar & 1.47 \\
Cottonwood \& aspen & 52.75 \\
Black walnut & 0.00 \\
Black cherry & 13.05 \\
Other hardwoods & 87.39 \\
Total all species & 1359.78 \\
\hline
\end{tabular}

One warning for developers of technologies that utilize woody biomass is that they must ensure that the technologies developed are robust enough to use the variety of wood fiber resources that are available in the Northeast forest. Kelty et al. [10] analyzed the productivity of five different stand types, each under three different site quality classes within Massachusetts. Each stand type was characterized by a different mix of species, including both hardwoods and softwoods. They found significant differences in both stocking densities and in biomass production across stand types and site quality. Different species, and even the same species across different sites, are characterized by different 
attributes including density, moisture content, bark content, presence of extractives, minerals, and ash content among other variables. Each processing technology using woody biomass is potentially affected by these differences.

In addition to the forest resource, some additional sources of woody biomass beyond the scope of this discussion include urban forestry, utility right-of-ways and landscaping residue. Another source, also outside our scope, is the wood derived from un-sustainable practices including land-clearing for development.

As noted above, additional woody biomass from the Northeast forest will likely be produced in conjunction with traditional harvesting of sawlogs, or with timber stand improvement. This material will be comprised of logging residues, and previously non-merchantable material due to poor form, species or size. As noted by Benjamin et al. [5], the Northeast benefits from a pre-existing logging and transportation infrastructure, but existing equipment was not designed for such material. Optimal handling of woody biomass requires different techniques and equipment than is used in traditional sawlog harvesting. The shortcoming of specialized equipment is the significant capital investment required by contractors.

In addition, the current logging workforce is aging and it is difficult to attract younger employees to this field of work [12]. For expansion to occur, the current forest products industry needs to be convinced of the future viability of an expanded biomass demand.

It is important to note however, that depending on relative pricing, some material that previously would have gone to traditional wood markets may be redirected to bioenergy or bioproduct facilities. Last year in Maine there was intense competition for raw material between bioenergy plants and hardwood pulp mills. As long as those facilities are competing for "pulp quality" chips, there is no change to forest operations or to post-harvest site conditions. That situation cannot be expected to occur and as woody biomass demands increase, so will the need for making informed tradeoffs between competing forest values. Additional guidelines may be required to assist landowners, loggers, and foresters with such decisions. As noted above, woody biomass harvests should be integrated with traditional harvest practices and as such it is important to ensure that new guidelines, policies, or regulations address forest conditions rather than specific products. Issues such as site productivity, water quality, and forest biodiversity are over-arching concerns that span all aspects of forest operations, and must therefore be addressed at the landscape level as well as sitespecific levels.

\section{Ecological sustainability}

For the most part, the forest cover and volume of trees in the Northeast states have been steadily increasing for the past 150 years $[5,13]$. From a tree volume perspective, this would seem to enable expanded harvest and production of forest products while maintaining a stable forest volume. However, Figure 1 shows that, in recent years, overall removals exceeded growth for all species combined [13]. This is likely due to unsustainable levels of softwood harvest of 
pulpwood in Maine that has occurred in the recent past [5]. There is much less use of hardwood species for pulp in the Northeast region, so much of the smalldiameter hardwood growing stock has been under-utilized for many years. Thus, hardwood growth exceeds removals, which helps to bring overall growth to within $6 \%$ of total removals.

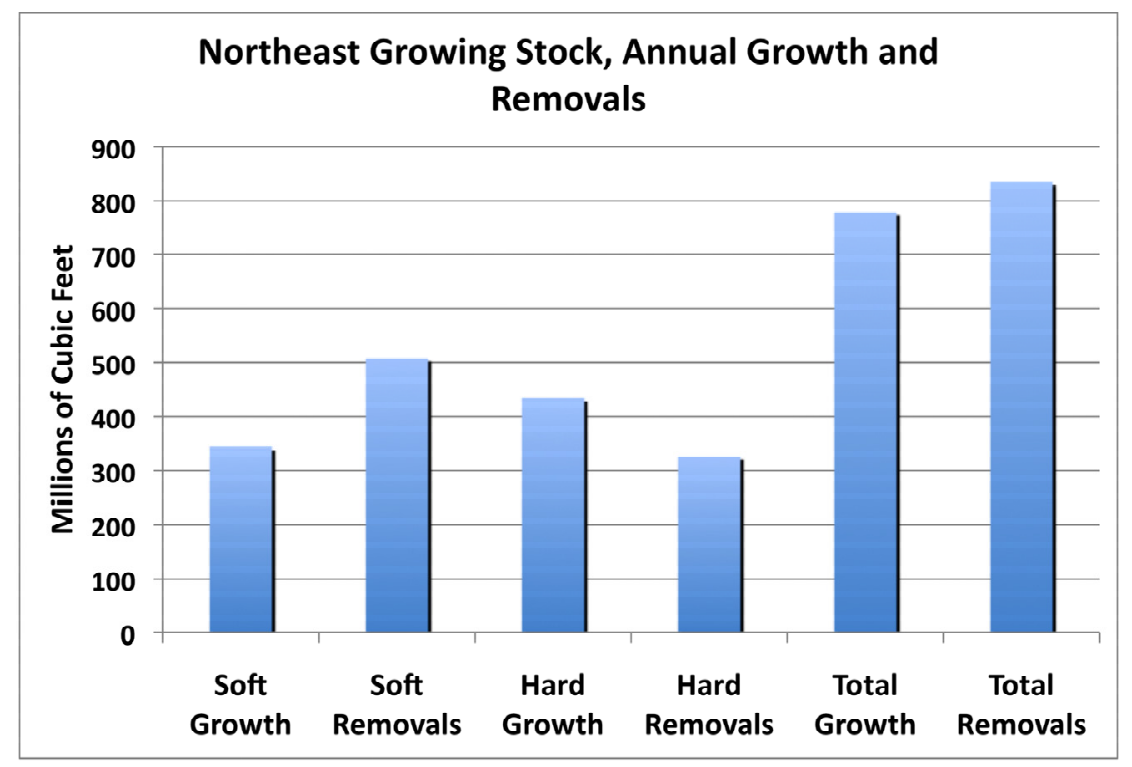

Figure 1: $\quad$ Forest growth to removals, 2008.

A sustainable level of production will provide to future generations substantially the same access to the forest resource we enjoy today. How to achieve this, and on what scale, is subject to debate. Substantial land conversion, from forest to housing development, continues throughout parts of the region [14]. Regulation of forest practices differ state-by-state [15]. Care should be taken to avoid "exporting" un-sustainable harvest practices to supply any local demand for forest biomass material [16]. One mechanism may be for producers to require that material be derived from certified sustainably managed forests. The region currently supports a growing acreage of certified forest lands [4].

Kelty et al. [10] have recently completed an analysis of the ecological sustainability of biomass in Massachusetts, focusing on the impacts of greatest concern - the conservation of nutrients on the site, and the protection of soils and streamwater quality. Nutrients are a critical part of the physiological requirements of trees that determine the rate of biomass production. Large quantities are removed in biomass harvests, both in the stems and in the branches and foliage (if whole-tree harvest methods are used). Regulations and/or best management practices are being developed in the states of the Northeast region to prevent excessive loss of nutrient stocks that would decrease future forest growth rates. Although there are differences among states, general principles are 
that whole-tree harvests should not be conducted on soils that are shallow to bedrock, sandy and infertile, on organic peats, or are on steep erodable sites. Some states may also require that a portion of the trees be left on the site, and stumps, roots, and forest floor material cannot be harvested. The Northeast is more susceptible to loss of nutrients because acid precipitation and nitrogen deposition (from industrial and agricultural sources) make soil nutrients more mobile, thus causing substantial amounts to leach from the soil into streams. These add to the loss of nutrients from harvest removals.

The concern about soils in biomass harvests is that the removal of the woody material may be too complete, such that the harvesting equipment may be moving across unprotected soils. This can lead to soil compaction, causing water to move over the surface and carry sediments into streams. Best management practices promote the use of logging slash to create a slash bed on harvest roads and trails that protect soils from compaction by harvest machinery.

\section{Social sustainability}

\subsection{Landowner attitudes}

Damery [15] summarized the literature relating to landowner attitudes toward forest harvesting and management planning. Private landowners, hold and manage land for a wide variety of reasons. This is particularly true among landowners of smaller parcels in the Northeast, where management for income from sawtimber ranks low compared to other values. These "other" values include: aesthetics, place of residence, recreation, and wildlife habitat - all of which rank higher than income from timber in a number of studies. A careful understanding of private landowner motivation will be needed if higher levels of forest biomass are sought from the Region's forests. Historically, private landowners have been reluctant to participate in formal forest management planning [15]. Between 1990 and 2002 the USDA Forest Service's Forest Stewardship Program attempted to increase the level of forest management planning among private non-industrial forest landowners. Despite extensive efforts, however, the cumulative percentage of private forest land that was brought under planning in the Northeast amounted to just $7.5 \%$ of total nonindustrial private forest acreage [15]. The lack of interest in active forest management will be a significant hurdle to overcome if the Region's sustainable production of forest biomass is to approach its full potential.

\subsection{Forest policy}

A growing array of policies at the state and federal levels seek to foster the development of industries using sustainably harvested forest biomass [17]. Stokes [18] lists nearly a dozen federal policies, mostly through DOE, that seek to foster biomass development. Many of these policies combine growing concern over energy costs, climate change, and the steady erosion of the US manufacturing sector with efforts to promote rural economic development $[9,19]$. 
At the federal level, the Energy Independence and Security Act (EISA), passed in December of 2007, calls for a five-fold increase in biofuel production over the next 15 years, with $60 \%$ (22 billion gallons/year) to be derived from cellulosic or non-corn feed stocks - including forest biomass. At the state level, the growing popularity of Renewable Portfolio Standards (RPS) is spurring interest in generating electricity from biomass. RPS policies, already adopted by Massachusetts, Connecticut, and Rhode Island, provide substantial price premiums for renewable energy providers in an effort to foster renewable energy while decreasing fossil fuel use, greenhouse gas emissions, and dependence on imported energy [19].

In combination, these policies promise to create both employment and income benefits for the Region. For example, Timmons et al. [9] estimated substantial economic gains from the future development of new biomass-fueled electricity generating facilities in Massachusetts. Another emerging technology is wood pellet manufacturing, which promises to create rural jobs, reduce energy costs, and recycle energy expenditures within state and local economies. In addition, efforts to revitalize the Region's aging pulp and paper mills through the colocation of biorefineries able to produce cellulosic ethanol have the potential to increase value-added and enhance competitiveness within the industry.

In promoting growth in these sectors, the speed of permitting new and/or expanded facilities has been identified as a key factor in economic feasibility [20]. Given the large capitalization costs and uncertainty of future markets, there are needs for tax credits and a clear, long-term commitment to nurturing the industry. Indeed, sustaining state and federal-level interest is a key factor in promoting the sector's growth - especially among investors that witnessed the rise and fall of the 1980s renewable energy boom.

Finally, policies seeking to enhance the use of forest biomass must operate within broader policy efforts designed to protect environmental quality. These long-standing policies include regulations over timber harvest practices, best management practices for the protection of water quality, certification standards, and regulations protecting shorelands, vernal pools and deer winter areas.

\section{Conclusions}

Demand for forest biomass in the Northeast is already substantial and increasing. State level government policy initiatives including Renewable Portfolio Standards as well as fossil fuel demand and supply dynamics will continue to spur demand for energy and fuels derived from forest biomass for the medium term future. Technologies vying for the forest biomass resource will serve a variety of needs including heat, electricity, combined heat and power, liquid fuels and others. Business developers intending to use forest biomass as a feedstock need to include this broad and changing market demand in their business planning process. Forest biomass users also need to be cognizant of the current supply constraints and in the variability of characteristics across the variety of species found in the Northeast forest. 
Key issues affecting the ecological sustainability of the forest biomass resource are no different than the concerns of traditional forestry. Practices should ensure the conservation of nutrients on the site, protect soils and maintain stream water quality. Site conditions vary widely but practitioners need to ensure that sufficient material is left in the woods to preserve long-term sustainability of the forest. In the Northeast forest one variable of particular concern is the maintenance of calcium levels in the soil. Different sites are likely to expose different constraints regarding forest removals.

An array of federal, state, and local policies, laws and regulations impact both the supply and demand for forest biomass. Their combined effects should be an important consideration in either individual business planning or biomass industry forecasting as a whole. The cost and timing of permitting will be a major determinant in the rollout of the emerging forest biomass industry. The balancing of economic, ecological and social concerns will remain a central focus for policy-makers and individuals interested in a sustainable forest biomass industry.

\section{Acknowledgement}

This project was supported by the University of Maine's Forest Bioproduct Research Initiative with funding provided in part by the National Science Foundation under Grant No. EPS-0554545.

\section{References}

[1] Barten, P., Damery, D., Catanzaro, P, Fish J., Campbell, S., Fabos, A. \& Fish, L. Massachusetts Family Forests: Birth of a Landowner Cooperative, Journal of Forestry 99(3) pp. 23-29, 2001.

[2] Table 1: Annual Estimates of the Resident Population for the United States, Regions, States, and Puerto Rico: April 1, 2000 to July 1, 2008 (NSTEST2008-01), Population Division, U.S. Census Bureau, Online. http://www.census.gov/popest/states/NST-ann-est.html

[3] Smith, B., Miles, P., Vissage, J. \& Pugh, S., Forest Resources of the United States, 2002, General Technical Report NC-241. St. Paul, MN: U.S. Dept. of Agriculture, Forest Service, North Central Research Station, 2004.

[4] DiMaio, J. \& O'Connor, R., The Massachusetts sustainable forest bioenergy initiative. The Pinchot Letter 12: 7-9, Pinchot Institute for Conservation, Washington, DC, USA, 2007.

[5] Benjamin, J., Lilieholm, R.J. \& Damery, D., Challenges and Opportunities for the Northeastern Forest Bioindustry, Journal of Forestry, in Press, 2009.

[6] Grace, R. \& Cory K., Massachusetts RPS: 2002 Cost Analysis Update Sensitivity Analysis. Massachusetts Division of Energy Resources, 2002. http://www.mass.gov/Eoeea/docs/doer/rps/cau-sap.pdf, Online 
[7] Table S1. Energy Consumption Estimates by Source and End-Use Sector, 2006, Energy Information Administration, U.S. Dept. of Energy, Online. http://www.eia.doe.gov/emeu/states/sep_sum/plain_html/sum_btu_1.html

[8] Beckert, E. \& Jakle, A. Renewable Energy Databook, September 2008, U.S. Dept. of Energy, Online. http://www1.eere.energy.gov/maps_data/ pdfs/eere_databook_091208.pdf

[9] Timmons, D., Damery, D., Allen, G. \& Petraglia, L., Energy from forest biomass: Potential economic impacts in Massachusetts. Massachusetts Division of Energy Resources, Boston, MA, USA. 30p. 2007.

[10] Kelty, M., D’Amato, A. \& Barten, P., Silvicultural and Ecological Considerations of Forest Biomass Harvesting in Massachusetts, Massachusetts Division of Energy Resources, Boston, MA, USA 65p. 2008.

[11] Eckardt, R., Forest harvesting systems for biomass production-Renewable biomass from the forests of Massachusetts, Massachusetts Division of Energy Resources, Boston, MA, USA. 87p. 2007.

[12] Eagan A. \& Taggart D., Who will log? Occupational choice and prestige in northern New England. Journal of Forestry, 102(1):20-25, 2004.

[13] U.S. Forest Service, Forest inventory and analysis. May, 2008. http://199.128.173.26/fido/mastf/index.html, Online

[14] Thorne, S. \& Sundquist, D., New Hampshire's Vanishing Forests: Conversion, Fragmentation and Parcelization of Forests in the Granite State. Society for the Protection of New Hampshire Forests, Concord, NH, USA. 153 p. 2001.

[15] Damery, D., Factors Influencing Forest Management Planning by Private Forest Landowners, PhD. Dissertation. University of Massachusetts, Amherst, USA. 2006.

[16] Berlik, M., Kittredge, D. \& Foster, D., The Illusion of Preservation: A global environmental argument for the local production of natural resources, Harvard Forest Paper 26., Harvard University, Petersham, Massachusetts, USA, 23 p. 2002

[17] Solomon, B.D., Barnes, J.R., \& Halvorsen, K.E.. Grain and cellulosic ethanol: 568 History, economics, and energy policy. Biomass and Bioenergy 31:416-425. 2007.

[18] Stokes, B. Forest Biomass Supply Chain, The Northeast Forest Bioproducts Proceedings, edited by Jeff Benjamin and David Damery, p.107-145, Forest Bioproducts Research Initiative, University of Maine. Orono, ME. 2007.

http://www.forestbioproducts.umaine.edu/conference forestbioproducts.php, Online

[19] Breger, D. The Role of Biomass in Serving Renewable Energy Portfolio Standards in New England, The Northeast Forest Bioproducts Proceedings, edited by Jeff Benjamin and David Damery, p.187-200 Forest Bioproducts Research Initiative, University of Maine. Orono, ME. 2007. http://www.forestbioproducts.umaine.edu/conference forestbioproducts.php, Online 
[20] Kingsley, E. Building the Forest Bioproducts Industry in the Northeast: Finding the Combinations that Fit., The Northeast Forest Bioproducts Proceedings, edited by Jeff Benjamin and David Damery, p.5-39, Forest Bioproducts Research Initiative, University of Maine. Orono, ME. 2007. $\mathrm{http}: / / \mathrm{www}$. forestbioproducts.umaine.edu/conference_forestbioproducts.ph $\mathrm{p}$, Online 